\title{
Progress and Opportunities for Strengthening Global Health Security
}

\author{
Frederick J. Angulo, Cynthia H. Cassell, Jordan W. Tappero, Rebecca E. Bunnell
}

$I^{n}$ n today's interconnected world, an infectious disease outbreak that is not rapidly detected and controlled at its source can become a costly global health threat, both in lives lost and economic turmoil $(1,2)$. Every year, thousands of outbreaks occur worldwide, many of which involve pathogens with pandemic potential. Since 2009, the World Health Organization (WHO) has declared public health emergencies of international concern for outbreaks of influenza $\mathrm{A}(\mathrm{H} 1 \mathrm{~N} 1)$ in 2009, Ebola in West Africa in 2014, and Zika in the Americas in 2015 (2). In 2007, the International Health Regulations 2005 (IHR 2005) entered into force, and all 196 state parties were legally bound to implement the core capacity required under the regulations. However, in 2014, almost two thirds of member states reported not being in compliance (3). To accelerate progress toward IHR 2005 compliance, the Global Health Security Agenda (GHSA) was launched by 29 countries, WHO, the Food and Agriculture Organization of the United Nations, and the World Organisation for Animal Health in 2014 and now includes $>60$ nations (4).

Also in 2014, the US government provided $\$ 6$ billion in emergency funding to end the Ebola epidemic in West Africa and to begin the implementation of GHSA as an initial 5-year initiative. The Centers for Disease Control and Prevention (CDC) received $\$ 1.8$ billion of these funds to contain Ebola in West Africa; these efforts included assistance for countries at risk for introduction of Ebola and support for work with partners to enhance global health security through GHSA implementation. As the need for action to rapidly control outbreaks and epidemics is increasingly recognized, it is useful to take stock of accomplishments and persisting gaps in global health security.

This special supplement of Emerging Infectious Diseases on global health security presents an inventory of key efforts by CDC, in collaboration with many partners, to foster health security worldwide, especially by strengthening national public health core capacities. This supplement

Author affiliation: Centers for Disease Control and Prevention, Atlanta, Georgia, USA

DOI: https://doi.org/10.3201/eid2313.171758 begins with several summary articles and then provides specific examples of global health security improvements in articles organized by sections entitled Prevent, Detect, and Respond.

Tappero et al. (4) and Fitzmaurice et al. (5) summarize selected CDC contributions to enhancing global health security from 1980 through 2017 and describe how expanded efforts under GHSA have been built on a framework created by the long history of CDC for capacity building efforts in selected partner countries. Another keynote article in the supplement describes how, after the 2014-2016 West Africa Ebola outbreak, Liberia, Sierra Leone, and Guinea have made substantial progress toward IHR 2005 implementation (6). To ensure credibility in the international effort to strengthen public health capacities for IHR 2005 compliance, WHO has developed and implemented the WHO Joint External Evaluation (JEE) tool (7). The JEE process is a vital independent global health security monitoring tool that through October 2017 has been implemented in 58 countries and is documenting both the advances toward, and gaps remaining, in national capacities for prevention, detection and control of public health threats $(5,7)$.

\section{Prevent}

Preventing the emergence and spread of infectious disease threats requires prevention and control of antimicrobial resistance, zoonotic diseases, vaccine-preventable diseases (VPDs), and their potential spread across international borders. Global efforts aimed at building national capacities for IHR 2005 compliance are complemented by targeted disease and country-specific efforts. For example, the Enhanced Gonococcal Antimicrobial Surveillance Program aims to inform country-specific treatment guidelines and enhance prevention and control efforts (8), and the President's Malaria Initiative's collaboration with the Antimalarial Resistance Monitoring in Africa Network supports the early detection of Plasmodium falciparum resistance to facilitate appropriate interventions (9).

Zoonoses prevention and control programs use a One Health approach with multisectoral collaboration between human and animal health. Several countries have 
conducted One Health prioritization exercises to identify their major zoonotic diseases (10), a critical step in efforts to control endemic zoonotic diseases (11). Ethiopia, the Democratic Republic of the Congo, and Georgia are all developing successful integrated zoonotic prevention and control programs (12).

Maintaining high population-wide vaccine coverage is a crucial prevention activity, particularly for VPD health security threats. For example, the failure to sustain high vaccine coverage led to a nationwide measles epidemic in Mongolia, a country previously verified as measles-free (13). VPD strategies include data improvement teams, which visit district health facilities and can result in improved vaccine administration data through evaluations and training efforts (14). Another approach for VPD is the Latin American Pertussis Project, a collaboration among 6 countries to address pertussis, a poorly controlled VPD in the region (15). Finally for antimicrobial resistance, zoonotic diseases, VPDs, and other public health threats, border health efforts aimed at preventing spread of communicable diseases across international boundaries are essential and have been used successfully $(16,17)$.

\section{Detect}

Global health security relies on all countries having $\geq 3$ capacities: 1) an adequate national public health laboratory capacity to safely transport and accurately evaluate biologic specimens with appropriate diagnostic testing methods, 2) a sustained and timely public health surveillance system, and 3) a trained competent workforce to conduct essential outbreak investigations. Although rapid laboratory confirmation of public health threats is a complex endeavor, requiring long-term technical assistance and major resources, many countries are advancing key components. For example, Ghana conducted a national public health laboratory system assessment in support of the Second Year of Life initiative for sustaining adequate vaccine coverage through 24 months of age and for monitoring GHSA-sponsored public health laboratory enhancement efforts (18). South Korea is enhancing its public health laboratory to meet the standards of the US Laboratory Response Network, which will facilitate the ability of this country to rapidly determine the etiology of most public emergencies (19).

Surveillance is the cornerstone for rapidly detecting public health threats. The WHO Early Warning Alert and Response Network is a major tool for conducting public health surveillance in humanitarian emergencies, including in refugee and displaced person camps (20). Other vital global health security assets are CDC regional Global Disease Detection centers in 10 countries that have provided novel public health surveillance and informatics contributions alongside laboratory research since 2001 (21). Other disease- and country-specific efforts have also informed best practices, including enhancing anthrax surveillance programs in anthrax-endemic countries (22) and use of alternative surveillance approaches, such as burial permit reviews, to describe cholera mortality rates in Tanzania during a 2016 epidemic (23).

Rapid detection of public health emergencies also requires an adequate public health workforce, particularly trained field epidemiologists, who can conduct timely and appropriate field investigations. The CDC international 2-year Field Epidemiology Training Program (FETP) began 35 years ago and has established 65 FETP programs in 90 countries, with $>3,900$ graduates of the 2-year field epidemiologist training (24). To meet the global health need for more trained field epidemiologists, particularly at the district level, training has been expanded in many countries to include a 3-month FETP-Frontline program (25). In 2014-2016, a total of 24 new FETP-Frontline programs were initiated with $>1,860$ participants (4).

\section{Respond}

Efficiently responding to public health emergencies is essential for preventing further disease spread and controlling outbreaks at their source. Outbreak responses worldwide have demonstrated the need for a structured incident management system, which is a critical component for a highly functional and efficient Emergency Operation Center. Many countries, particularly GHSA partner countries, have enhanced their emergency response capacity by establishing emergency operation centers with a strong incident management system foundation $(26,27)$. Complex humanitarian emergencies frequently involve the most difficult settings, including fragile states and areas of conflict, and recent case studies illustrate the difficulty of supporting a sustained response in such settings (28). After the 20142016 West Africa Ebola epidemic, CDC established the Global Rapid Response Team (GRRT) to ensure a ready force of trained responders. In the first 16 months, GRRT members deployed 291 times to 35 countries (29). Medical countermeasures, which are medical interventions aimed at controlling public health emergencies, can be essential for rapid response and containment and include using vaccination during outbreaks of cholera, typhoid, yellow fever, and Ebola virus disease (30).

\section{Conclusions}

Global health security relies on IHR 2005 compliance by all countries and, as such, remains an unfinished journey (31). Although much has been accomplished through the first years of GHSA implementation, JEEs around the world highlight numerous prevent, detect, and respond capabilities that still need strengthening. Also lacking is an evidence base of the most effective, timely, and cost-effective approaches to building national capacities for IHR 2005 
compliance. As countries and partners continue their work to build health security capabilities, there will be useful opportunities to evaluate different implementation strategies and to document the impact of newly acquired capacities. Continuing this work and thereby sustaining this momentum toward IHR 2005 compliance is critical for protecting Americans and other persons worldwide.

\section{Dr. Angulo is Associate Director for Science in the Division of Global Health Protection, Center for Global Health, Centers for Disease Control and Prevention, Atlanta, GA. His research interests include antimicrobial resistance, burden of diseases, and international capacity building efforts for global health security.}

Dr. Cassell is Acting Associate Director for Applied Research and Evaluation, Division of Global Health Protection, Center for Global Health, Centers for Disease Control and Prevention, Atlanta, GA. Her research interests include surveillance, health information systems, global health, and health services research.

\section{Dr. Tappero is Senior Advisor for Global Health, Division of} Global Health Protection, Center for Global Health, Centers for Disease Control and Prevention, Atlanta, GA. His research interests include HIV/AIDS, tuberculosis, malaria, neglected tropical diseases, meningococcal disease, leptospirosis, Ebola and Marburg viruses, cholera, and other emerging infections.

Dr. Bunnell is Deputy Director for Science, Policy, and Communication, Division of Global Health Protection, Center for Global Health, Centers for Disease Control and Prevention, Atlanta, GA. Her research interests include global health surveillance, HIV/AIDS, tobacco use prevention, and global health security capacity building.

\section{References}

1. Heymann DL, Chen L, Takemi K, Fidler DP, Tappero JW, Thomas MJ, et al. Global health security: the wider lessons from the West African Ebola virus disease epidemic. Lancet. 2015;385:1884-901. http://dx.doi.org/10.1016/ S0140-6736(15)60858-3

2. Frieden TR, Tappero JW, Dowell SF, Hien NT, Guillaume FD, Aceng JR. Safer countries through global health security. Lancet. 2014;383:764-6. http://dx.doi.org/10.1016/ S0140-6736(14)60189-6

3. Gostin LO, Katz R. The International Health Regulations: the governing framework for global health security. Milbank Q. 2016;94:264-313. http://dx.doi.org/10.1111/1468-0009.12186

4. Tappero JW, Cassell CH, Bunnell BE, Angulo FJ, Craig A, Pesik N, et al.; Global Health Security Science Group. US Centers for Disease Control and Prevention and its partners' contributions to global health security. Emerg Infect Dis. 2017; 23(Suppl):S5-14.

5. Fitzmaurice AG, Mahar M, Moriarty LF, Bartee M, Hirai M, Li W, et al.; GHSA Implementation Group. Contributions of the US Centers for Disease Control and Prevention in implementing the Global Health Security Agenda in 17 partner countries. Emerg Infect Dis. 2017;23(Suppl):S15-24.

6. Marston BJ, Dokubo EK, van Steelandt A, Martel L, Williams D, Hersey S, et al. Ebola response impact on public health programs, West Africa, 2014-2017. Emerg Infect Dis. 2017;23(Suppl):S25-32.

7. Bell E, Tappero JW, Ijaz K, Bartee M, Fernandez J, Burris H, et al. Joint External Evaluation- development and scale-up of a global multisectoral health capacity evaluation process. Emerg Infect Dis. 2017;23(Suppl):S33-9.

8. Weston EJ, Wi T, Papp J. Surveillance for antimicrobial drugresistant Neisseria gonorrhoeae through the Enhanced Gonococcal Antimicrobial Surveillance Program. Emerg Infect Dis. 2017; 23(Suppl):S47-52.

9. Halsey ES, Venkatesan M, Plucinski MM, Talundzic E, Lucchi NW, Zhou Z, et al. Capacity development through the US President's malaria initiative-supported antimalarial resistance monitoring in Africa network. Emerg Infect Dis. 2017;23(Suppl):S53-6.

10. Salyer SJ, Silver R, Simone K, Barton-Behravesh C. Prioritizing zoonoses for global health capacity building - themes from One Health zoonotic disease workshops in 7 countries, 2014-2016. Emerg Infect Dis. 2017;23(Suppl):S57-64.

11. Belay ED, Kile JC, Hall AJ, Barton-Behravesh C, Parsons MB, Salyer S, et al. Zoonotic disease programs for enhancing global health security. Emerg Infect Dis. 2017;23(Suppl):S65-70.

12. Shiferaw ML, Doty JB, Maghlakelidze G, Morgan J, Khmaladze E, Parkadze O, et al. Frameworks for preventing, detecting, and controlling zoonotic diseases. Emerg Infect Dis. 2017;23(Suppl):S71-6.

13. Hagan JE, Greiner A, Luvsansharav UO, Lake J, Lee C, Pastore R, et al. Use of a diagonal approach to health system strengthening and measles elimination after a large nationwide outbreak in Mongolia. Emerg Infect Dis. 2017;23(Suppl):S77-84.

14. Ward K, Mugenyi K, Benke A, Luzze H, Koyzira C, Immaculate A, et al. Enhancing workforce capacity to improve vaccination data quality, Uganda. Emerg Infect Dis. 2017;23(Suppl):S85-93.

15. Pinell-McNamara V, Acosta AM, Pedreira MC, Carvalho AF, Pawloski L, Tondella ML, et al. Expanding pertussis epidemiology in 6 Latin American countries through the Latin American Pertussis Project. Emerg Infect Dis. 2017;23(Suppl):S94-100.

16. Vonnahme LA, Jungerman MR, Gulati RK, Illig P, Francisco Alvarado-Ramy F. US federal travel restrictions for persons with higher-risk exposures to communicable diseases of public health concern. Emerg Infect Dis. 2017;23(Suppl):S108-113.

17. Merrill RD, Rogers K, Ward S, Ojo O, Kakaī CG, Agbeko TT, et al. Responding to communicable diseases in internationally mobile populations at points of entry and along porous borders, Nigeria, Benin, and Togo. Emerg Infect Dis. 2017;23(Suppl):S114-120.

18. Ogee-Nwankwo A, Opare D, Boateng G, Nyaku M, Haynes LM, Balajee SA, et al. Assessment of national public health and reference laboratory, Accra, Ghana, within framework of global health security. Emerg Infect Dis. 2017;23(Suppl):S121-5.

19. Parker JT, Juren AC, Lowe L, Santibañez S, Rhie G, Merlin T. Enhancing laboratory response network capacity in South Korea. Emerg Infect Dis. 2017;23(Suppl):S126-30.

20. Cordes KM, Cookson ST, Boyd AT, Hardy C, Malik MR, Mala P, et al. Real-time surveillance in emergencies using the early warning alert and response network. Emerg Infect Dis. 2017;23 (Suppl):S131-7.

21. Rao CY, Goryoka GW, Henao OL, Clarke KR, Salyer SJ, Montgomery JM. Global disease detection-Achievements in applied public health research, capacity building, and public health diplomacy, 2001-2016. Emerg Infect Dis. 2017;23(Suppl):S138-146.

22. Vieira AR, Salzer JS, Traxler RM, Hendricks KA, Kadzik M, Marston CK, et al. Enhancing surveillance and diagnostics in anthraxendemic countries. Emerg Infect Dis. 2017;23(Suppl):S147-153.

23. McCrickard LS, Massay AE, Narra R, Mghamba J, Mohamed AA, Kishimba RS, et al. Cholera mortality during urban epidemic, Dar es Salaam, Tanzania, August 6, 2015-January 16, 2016. Emerg Infect Dis. 2017;23(Suppl):S154-7. 
24. Jones DS, Dicker RC, Fontaine RE, Boore AL, Omolo JO, Ashgar RJ, et al. Building global epidemiology and response capacity. Emerg Infect Dis. 2017;23(Suppl):S158-165.

25. McKenzie André, A, Lopez A, Perkins S, Lambert S, Chase L, Pedalino B. Frontline field epidemiology training programs as a strategy to improve disease surveillance and response. Emerg Infect Dis. 2017;23(Suppl):S166-73.

26. Brencic DJ, Pinto M, Gill A, Kinzer MH, Hernandez L, Pasi OG CDC support for global public health emergency management. Emerg Infect Dis. 2017;23(Suppl):S183-89.

27. Balajee A, Pasi OG, Etoundi AG, Rzeszotarski P, Thuy Do T, Hennessee I, et al. Sustainable model for public health Emergency Operations Centers for global settings. Emerg Infect Dis. 2017;23(Suppl):S190-5.

28. Boyd AT, Cookson ST, Anderson B, Bilukha OO, Brennan M, Handzel R, et al. Centers for Disease and Control Prevention response to humanitarian emergencies, 2007-2016. Emerg Infect Dis. 2017;23(Suppl):S196-202.

29. Stehling-Ariza T, Calles D, Djawe K, Garfield R, Gerber M, Ghiselli M, et al. Establishment of CDC Global Rapid Response Team. Emerg Infect Dis. 2017;23(Suppl):S203-9.

30. Walldorf JA, Date K, Sreenivasan N, Harris J, Hyde T. Lessons learned from emergency response vaccine efforts for cholera, typhoid, yellow fever, and Ebola. Emerg Infect Dis. 2017;23 (Suppl):S210-16.

31. Osterholm M. Global health security —an unfinished journey. Emerg Infect Dis. 2017;23(Suppl):S225-7.

Address for correspondence: Frederick J. Angulo, Centers for Disease Control and Prevention, 1600 Clifton Rd NE, Mailstop D68, Atlanta, GA, 30329-4027, USA; email: fja0@cdc.gov

\section{April 2013: Emerging Viruses}

- Discrepancies in Data Reporting for Rabies, Africa

- Circovirus in Tissues of Dogs with Vasculitis and Hemorrhage

- Cost-effectiveness of Novel System of Mosquito Surveillance and Control, Brazil

- Serotype IV and Invasive Group B Streptococcus Disease in Neonates, Minnesota, 2000-2010

- Transmission of Hepatitis E Virus from Rabbits to Cynomolgus Macaques

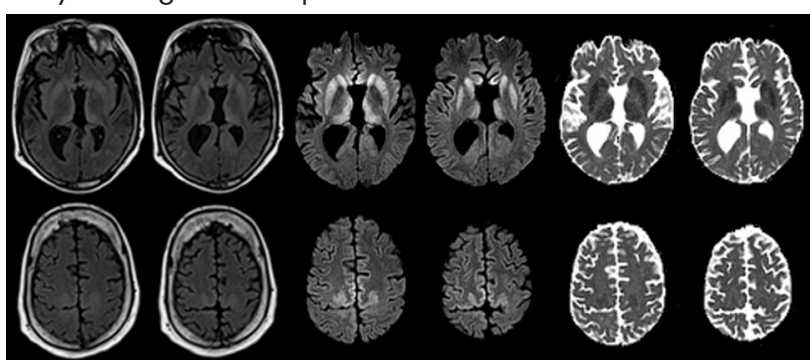

- Description and Nomenclature of Neisseria meningitidis Capsule Locus

- Henipaviruses and Fruit Bats, Papua New Guinea

- Detection of Spliced mRNA from Human Bocavirus 1 in Clinical Samples from Children with Respiratory Tract Infections

- Predicting Hotspots of Influenza Reassortment

- Effect of 10-Valent Pneumococcal Vaccine on Childhood Pneumonia, Brazil

- Occult Hepatitis B Virus Infection in Chacma Baboons, South Africa

- Deaths Associated with Influenza Pandemic of 1918-19, Japan

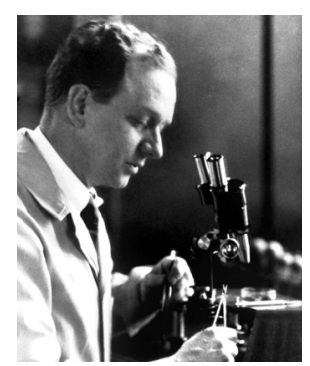

- Response to Rabies Epidemic, Bali, Indonesia, 2008-2011

- Hepatitis Virus in Long-Fingered Bats, Myanmar

- Methicillin-Resistant Staphylococcus aureus Colonization of the Groin and Risk for Clinical Infection among HIV-infected Adults

- Feline Origin of Rotavirus Strain, Tunisia, 2008

- Rabies Update for Latin America and the Caribbean

- Risk Factors for Influenza among Health Care Hospital Workers during 2009 Pandemic, Toronto, Ontario, Canada

- Control of Foot-and-Mouth Disease during 2010-2011 Epidemic, South Korea

- Tick-borne Encephalitis Virus in Horses, Austria, 2011

- Hand, Foot, and Mouth Disease Caused by Coxsackievirus A6, Thailand, 2012

- Early Introduction and Delayed Dissemination of Pandemic Influenza, Gabon

- Powassan Virus Encephalitis, Minnesota, USA

- Control of Foot-and-Mouth Disease during 2010-2011 Epidemic, South Korea

- Novel Serotype of Bluetongue Virus, Western North America

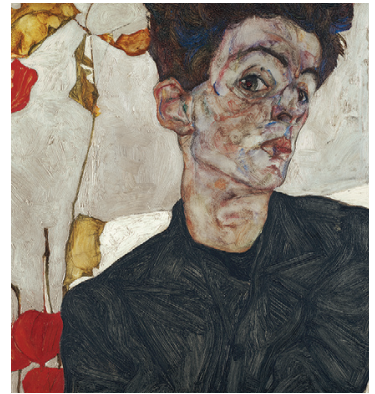

